\title{
Subclinical hyperthyroidism in the course of autonomous nodules - clinical evaluation
}

\author{
Grzegorz Rudzki', Monika Lenart-Lipińska', Agata Smoleń², Beata E. Chrapko ${ }^{3}$, \\ Beata Matyjaszek-Matuszek ${ }^{1}$ \\ ${ }^{1}$ Department of Endocrinology, Medical University of Lublin, Poland \\ ${ }^{2}$ Department of Epidemiology and Clinical Research Methodology, Medical University of Lublin, Poland \\ ${ }^{3}$ Department of Nuclear Medicine, Medical University of Lublin, Poland
}

\begin{abstract}
Introduction: Subclinical hyperthyroidism ( $\mathrm{SCH}$ ), also known as mildly symptomatic hyperthyroidism, has recently been diagnosed more frequently. One of the main endogenous causes of this disorder is autonomously functioning thyroid nodule (AFTN). Despite the fact that it is usually asymptomatic, SCH entails repercussions on the cardiovascular system and bone, and it carries a risk of progression to overt hyperthyroidism with a typical clinical picture. Treatment is still controversial, and its benefits are widely debated in literature. Material and methods: From 459 patients authors selected a group of 49 patients (10.6\% of all subjects with hyperthyroidism), 41 women $(83.7 \%)$ with AFTN at the stage SCH treated in the Outpatient Endocrinological Clinic and the Department of Endocrinology of the Medical University of Lublin over a three-year period. The method applied in the study was a retrospective analysis of medical records with a particular account of medical history, physical examination, and additional tests obtained during the process of diagnostic and therapeutic procedures.

Results: Forty-one patients (83.7\%) suffered from typical symptoms of hyperthyroidism; only eight patients (16.3\%) were asymptomatic. The most frequently reported symptoms were tachycardia in women $(51.2 \%)$ and anxiety in men $(50 \%)$. The type of thyrostatic drugs and the length of therapy did not affect the outcome of iodine-131 therapy. In the vast majority of the patients (87.8\%) radioidodine therapy was effective; 30 patients $(61.2 \%)$ reached euthyreosis and 13 patients $(22.5 \%)$ developed hypothyroidism.

Conclusions: Most patients with SCH in the course of AFTN suffered from typical symptoms of overt hyperthyroidism; only every sixth patient was asymptomatic. The volume of autonomous adenomas did not affect the result of ${ }^{131}$ I therapy; however, the impact of AFTN volume as well as the thyroid volume on RIT efficacy requires futher investigation. In the vast majority of patients ${ }^{131}$ I therapy was an effective method of treatment, and an earlier therapeutic effect was observed more often in the patients with focal lesions located in the right lobe. (Endokrynol Pol 2019; 70 (2): 157-164)
\end{abstract}

Key words: subclinical hyperthyroidism; SCH; autonomous nodule; AFTN; ${ }^{131}$ l; radioiodine therapy

\section{Introduction}

Subclinical hyperthyroidism (SCH), also called mildly symptomatic hyperthyroidism, in the past years has been diagnosed more frequently. One of the main endogenous causes of this disorder is autonomously functioning thyroid nodule (AFTN) [1, 2]. Diagnosis is established only under certain laboratory criteria, i.e. persistently low TSH level confirmed with third-generation tests and normal level of free thyroid hormones [3]. AFTN, defined as a hot nodule in thyroid scintigraphy, is characterised by excessive production of hormones, which suppresses TSH secretion and leads to inhibition of hormone synthesis by the remainder of the gland and results in either overt or subclinical hyperthyroidism. It is usually a benign follicular lesion $(90-95 \%)$ or a hyperplastic nodule (5-10\%), less often autonomous carcinoma, irrespective of the activity of the hypothalamic-pituitary-adrenal axis [4,5]. SCH has gained more attention after publication of the results of a systematic review with a meta-analysis of 10 prospective cohort studies from 2012, pointing to its association with higher total and cardiovascular mortality as well as atrial fibrillation as compared to healthy controls $[6,7]$. However, it is emphasised that over $25 \%$ of such nodules do not produce symptoms of general thyrotoxicosis. $\mathrm{SCH}$ may take the form of a primary onset of the disorder leading to overt hyperthyroidism accompanied by few or even no clinical symptoms. They are mainly associated with cardiovascular diseases like tachycardia or supraventricular arrhythmia, detected in electrocardiographic investigation [8]. An analysis of the clinical symptoms reported by the patients may give valuable information about the expected clinical course of AFTNs. Despite potential cardiovascular and bone complications or even progression to overt hyperthyroidism, the need to treat $\mathrm{SCH}$ is still debatable. Treating this form of disease is currently perceived as 
controversial, and arbitrary recommendations of international endocrine associations are questioned by many experts in the field. At the same time the evaluation of the benefits from SCH treatment is often ambiguously presented in literature [9].

The main objective of the study was to evaluate the clinical picture of AFTNs in SCH and its optimal treatment.

\section{Material and methods}

\section{Study protocol}

The method applied in the study was a retrospective analysis of medical records with a particular account of medical history, physical examination, and additional tests obtained during the process of diagnostic and therapeutic procedures.

Medical records of the patients were evaluated for:

- age at diagnosis (patient's age) and duration of the disease;

- family history of thyroid disease;

- subjective clinical signs and co-morbidities;

- $\mathrm{TSH}, \mathrm{FT}_{4}$, and $\mathrm{FT}_{3}$ levels at diagnosis and during treatment;

- presence of antithyroid antibodies: anti-thyroid peroxidase antibodies, (anti-TPO antibodies), and TSH-receptor autoantibodies (TRAb):

— thyroid ultrasound and scintiscans;

- ultrasound-guided fine-needle aspiration biopsy (FNAB);

- method of treatment before radioiodine therapy (RIT, ${ }^{131} \mathrm{I}$ );

- qualification for treatment with RIT;

- evaluation of patient's prognosis after RIT.

The patients underwent physical examination for typical clinical signs of hyperthyroidism.

Diagnosis of SCH was confirmed with the levels of TSH, $\mathrm{FT}_{4}$, and $\mathrm{FT}_{3}$ in accordance with the endocrinological standards. Other causes of low TSH were excluded. They were: overt hyperthyroidism, gestation, thyroiditis, mental illness, central hypothyroidism, and secondary thyroid syndromes in the course of neoplasms, fever, liver disease, and starvation.

The results of biochemical tests and diagnostic imaging (thyroid ultrasound and scintigraphy) performed at the Radiology and Nuclear Medicine Centre of the Medical University of Lublin were used in the study.

In accordance with the recommendations of the Scientific Committee of the Scientific Conference "Thyroid Cancer", 32 patients (65\%) with suspected focal lesions diagnosed by palpation and/or with thyroid ultrasound underwent FNAB. Family history included the prevalence of thyroid disease in first-degree relatives.

\section{Study population}

Initially, we reviewed a group of 459 patients with diagnosed hyperthyroidism (ICD E.05) treated in the Outpatient Endocrinological Clinic and the Department of Endocrinology of the Medical University of Lublin during a three-year-long period, i.e. from October 2010 to June 2013. Next, a group of 291 (63.4\%) patients with a toxic goitre was pooled. From this group we singled out 49 patients (10.6\% of all subjects with hyperthyroidism), 41 women $(83.7 \%)$ and 8 men $(16.3 \%)$, who suffered from AFTN and were qualified for ${ }^{131}$ I treatment, as shown in Figure 1. We excluded patients with contraindications to ${ }^{131} \mathrm{I}$ therapy, with either relative ones (uncontrolled hyperthyroidism, excessive iodine intake induced hyperthyroidism, patients younger than 16 years of age) or with absolute ones (gestation, breastfeeding).

\section{Methods of laboratory test measurements}

Blood serum level of TSH was measured by immunoradiometric assay (B.R.A.H.M.S TSH 1 RIA). The levels of $\mathrm{FT}_{3}$ and $\mathrm{FT}_{4}$ in serum

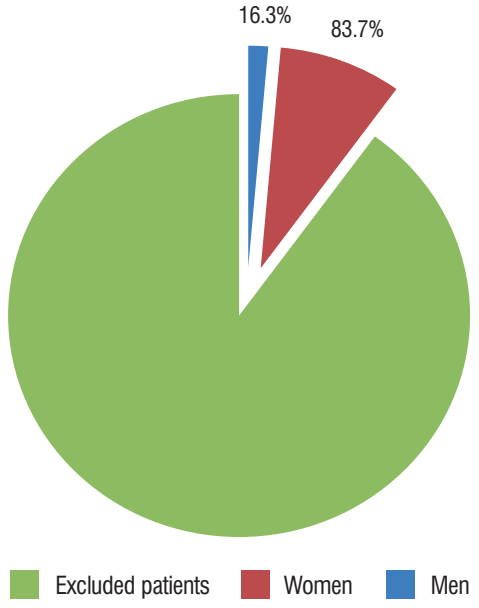

Figure 1. Phenotype analysis of the study group

were determined by radioimmunoassay (RIA) with solid phase antigen radioimmunometric technique (SPART) (B.R.A.H.M.S FT SPART RIA, B.R.A.H.M.S FT 4 RIA) with the use of a coated-tube system. The level of TRAb/TSI was measured by radioreceptor assay (RRA) used for the quantitative method of measurement of TRAb (B.R.A.H.M.S) using a human TSH receptor (B.R.A.H.M.S Track human RIA). The levels of antibodies against thyroid peroxidase were determined by RIA with the B.R.A.H.M.S anti-TPO RIA kit.

\section{Methods of imaging}

Thyroid ultrasound was performed using a 7.5-MHz linear probe for the LOGIQ P5 machine. A solution of $74 \mathrm{MBq}$ of ${ }^{99 \mathrm{~m}} \mathrm{TcO} 4$ was injected intravenously. Scintigraphy was performed using a gamma camera with a small field of view. For ${ }^{131}$ I uptake test, capsules of 4 $\mathrm{MBq}$ of sodium iodide $\mathrm{Na}^{131} \mathrm{I}$ were administered orally, and iodine uptake was measured after 24,48 , and 72 hours.

\section{Ultrasound-guided fine-needle aspiration biopsy}

In accordance with the recommendations of the Scientific Committee of the Scientific Conference "Thyroid Cancer", 32 patients $(65 \%)$ with suspected focal lesions diagnosed by palpation and/or with thyroid ultrasound underwent ultrasound-guided FNAB [10].

\section{Radioiodine therapy}

The therapeutic activity of ${ }^{131} \mathrm{I}$ was calculated on the basis of Marinelli's formula, in which a dose 300 Gy was for each gram of hyperactive thyroid tissue. The subjects with AFTNs were qualified to RIT in accordance with the official recommendations.

\section{Criteria for recovery and rules for monitoring patients after} administrating ${ }^{131} I$

Criteria of recovery included normal thyroid function (TSH, $\mathrm{FT}_{4^{\prime}}$ and $\mathrm{FT}_{3}$ levels within range) as well as a less expected effect of treatment i.e. hypothyroidism. All patients were evaluated for possible complications, in particular: aggravation of hyperthyroid symptoms including atrial fibrillation, circulatory failure, thyroid crisis, radiation-induced thyroiditis, and symptoms of sialadenitis. In accordance with the procedure of ${ }^{131}$ I therapy, each patient was monitored in an outpatient clinic at certain intervals i.e. after one, three, six, and 12 months.

\section{Statistical analysis}

The values of non-measurable parameters were presented by means of numbers and percentages, whereas the measurable ones used the arithmetic mean, standard deviation, median, as well as the $25^{\text {th }}$ and $75^{\text {th }}$ percentile along with the range of variability. To evaluate 
Table I. Characteristics of the study group

\begin{tabular}{|c|c|c|c|c|c|c|c|}
\hline Parameter & \multicolumn{2}{|c|}{ Women median (range) } & \multicolumn{2}{|c|}{ Men median (range) } & \multicolumn{2}{|c|}{ Total median (range) } & $\mathbf{p}$ \\
\hline Age [years] & \multicolumn{2}{|c|}{$59.0(52.00-67.00)$} & \multicolumn{2}{|c|}{$63.5(56.00-75.00)$} & \multicolumn{2}{|c|}{$59.0(52.00-68.00)$} & 0.28 \\
\hline Treatment length [months] & \multicolumn{2}{|c|}{$3.00(0.00-6.00)$} & \multicolumn{2}{|c|}{$2.5(0.00-7.50)$} & \multicolumn{2}{|c|}{$3.00(0.00-7.00)$} & 1.0 \\
\hline $\begin{array}{l}\text { Period of time from } \\
\text { scintigraphy to iodine } \\
\text { administration [days] }\end{array}$ & \multicolumn{2}{|c|}{$37.0(15.00-113.00)$} & \multicolumn{2}{|c|}{$36.00(28.00-66.00)$} & \multicolumn{2}{|c|}{$37.0(17.00-93.00)$} & 0.78 \\
\hline $\begin{array}{l}\text { Patients treated } \\
\text { with thyrostatics }\end{array}$ & \multicolumn{2}{|c|}{$\begin{array}{c}25(60.9 \%) \\
\text { (51.0\% of all patients) }\end{array}$} & \multicolumn{2}{|c|}{$\begin{array}{c}5(62.5 \%) \\
\text { (10.2\% of all patients) }\end{array}$} & \multicolumn{2}{|c|}{$\begin{array}{c}30 \\
\text { (61.2\% of all patients) }\end{array}$} & 0.75 \\
\hline TSH before treatment $[\mathrm{mlU} / \mathrm{L}]$ & \multicolumn{2}{|c|}{$<0.04(0.04-0.25)$} & \multicolumn{2}{|c|}{$<0.04(0.04-0.04)$} & \multicolumn{2}{|c|}{$<0.04(0.04-0.18)$} & 0.37 \\
\hline $\mathrm{FT}_{4}$ before treatment $[\mathrm{pmol} / \mathrm{L}]$ & \multicolumn{2}{|c|}{$18.00(15.70-19.40)$} & \multicolumn{2}{|c|}{$16.65(15.60-21.00)$} & \multicolumn{2}{|c|}{$17.60(15.70-19.40)$} & 0.60 \\
\hline $\mathrm{FT}_{3}$ before treatment $[\mathrm{pmol} / \mathrm{L}]$ & \multicolumn{2}{|c|}{$6.30(5.80-6.70)$} & \multicolumn{2}{|c|}{$6.50(6.00-8.70)$} & \multicolumn{2}{|c|}{$6.30(5.80-6.80)$} & 0.27 \\
\hline aTPO [U/mL] & \multicolumn{2}{|c|}{$30.9(21.45-75.7)$} & \multicolumn{2}{|c|}{$53.00(26.00-67.5)$} & \multicolumn{2}{|c|}{$33.25(22.1-75.2)$} & 0.73 \\
\hline $\mathrm{TSI}[\mathrm{U} / \mathrm{mL}]$ & \multicolumn{2}{|c|}{$0.30(0.30-0.60)$} & \multicolumn{2}{|c|}{$0.35(0.3-0.65)$} & \multicolumn{2}{|c|}{$0.3(0.3-0.6)$} & 0.57 \\
\hline $\begin{array}{l}\text { Volume of the whole thyroid } \\
{[\mathrm{mL}]}\end{array}$ & \multicolumn{2}{|c|}{$29.22(15.19-42.23)$} & \multicolumn{2}{|c|}{$46.75(23.81-68.91)$} & \multicolumn{2}{|c|}{$32.23(16.09-47.82)$} & 0.09 \\
\hline Size of the right lobe $[\mathrm{mL}]$ & \multicolumn{2}{|c|}{$13.01(7.22-24.58)$} & \multicolumn{2}{|c|}{$23.92(11.59-46.68)$} & \multicolumn{2}{|c|}{$13.1(8.87-29.49)$} & 0.13 \\
\hline Size of the left lobe $[\mathrm{mL}]$ & \multicolumn{2}{|c|}{$9.22(5.48-19.59)$} & 7.511 & $-49.36)$ & $9.22(5$ & -19.59) & 0.81 \\
\hline Volume of adenoma [mL] & 4.24 ( & $-8.88)$ & 4.971 & $-36.90)$ & 4.241 & $-9.25)$ & 0.39 \\
\hline $\begin{array}{l}\text { Size of adenoma } \\
\text { in the thyroid (\%) }\end{array}$ & $(16.92 \%)$ & $74-2.65)$ & $(23.32 \%)$ & $2-44.74)$ & $(17.1 \%)$ & $2-34.51)$ & 0.42 \\
\hline Location of adenoma & $\begin{array}{l}\text { Left lobe } \\
20(48.8 \%)\end{array}$ & $\begin{array}{l}\text { Right lobe } \\
21(51.2 \%)\end{array}$ & $\begin{array}{l}\text { Left lobe } \\
0(0 \%)\end{array}$ & $\begin{array}{l}\text { Right lobe } \\
8(100 \%)\end{array}$ & $\begin{array}{l}\text { Left lobe } \\
20(40.8 \%)\end{array}$ & $\begin{array}{l}\text { Right lobe } \\
29(59.2 \%)\end{array}$ & 0.03 \\
\hline Ultrasound-guided FNAB & 26 & $4 \%)$ & & & 32 & 3\%) & 0.82 \\
\hline
\end{tabular}

TSH — thyroid stimulating hormone; FT3 — free triiodothyronine; FT4 — free thyroxine; aTPO — anti-thyroid peroxidase antibodies; TSI — thyroid stimulating immunoglobulin; FNAB - ultrasound-guided fine-needle aspiration biopsy; Data are presented as median (interquartile range) and N (\%)

statistical differences and correlations between the non-measurable parameters, cross tabulation and a chi-squared test were applied. While, to compare the measurable variables, we performed the Mann-Whitney U test for two independent groups, whereas the Kruskal-Wallis test and a post-hoc analysis were used for multiple comparisons. The adopted significance level was 5\%. The statistical analysis was performed with the StatSoft, Poland Statistica v. 10.0 software.

\section{Results}

\section{Clinical characteristics of the study group}

The median age in women was insignificantly lower than in men, whereas the median of the time of observation between qualification procedures and RIT in the whole group was 37 days, which was insignificant in terms of gender (Tab. I). Only nine patients (18.4\%) reported family history of thyroid disease. Further evaluation showed that the time median was three months and the duration of treatment in women was insignificantly longer than in men, as shown in Table I. In the study group 30 patients $(61.2 \%)$ were treated with thyrostatics, as shown in Table I.

\section{Thyroid characteristics of the study group}

Thyroid evaluation of the study group included both the results of imaging and biochemical tests, as shown in Table I. TSH level before the treatment in the whole study group was suppressed, while $\mathrm{FT}_{4}$ and $\mathrm{FT}_{3}$ levels were normal. Both in women and in men the right lobe was larger. However, the volume of the left lobe in women was insignificantly greater than in men. The mean volume of the autonomous adenoma was $4.24 \mathrm{ml}$ (1.27-9.25 ml) with no significant difference in terms of gender, which constituted $16.9 \%$ and $23.3 \%$ of the whole thyroid tissue in women and men, respectively. In most of the patients (29 subjects, $59.2 \%$ ) adenoma was located in the right lobe, whereas in 20 subjects $(40.8 \%)$ it was in the left lobe. In all men the nodule was found in the right lobe, and in women it was distributed equally. Thyroid FNAB was performed in 32 patients, which constituted $65 \%$ of the whole group, i.e. in $75 \%$ of men and $63.4 \%$ of women. All biopsy specimens were found benign.

\section{Clinical symptoms in the course of $\mathrm{SCH}$}

Forty-one patients $(83.7 \%$ ) suffered from typical symptoms of hyperthyroidism, and only eight patients $(16.3 \%)$ were asymptomatic. The most frequently reported symptom in women was tachycardia $(51.2 \%)$ while in men $(50 \%)$ it was anxiety — as shown in Table II. 
Table II. Clinical symptoms in the study group

\begin{tabular}{|c|c|c|c|}
\hline \multirow{2}{*}{ Symptoms } & Women & Men & Total \\
\hline & $\mathbf{N}(\%)$ & $\mathbf{N}(\%)$ & $\mathbf{N}(\%)$ \\
\hline Periodical heart palpitation & $21(51.2 \%)$ & $3(37.5 \%)$ & $24(49 \%)$ \\
\hline Weakness & $20(48.9 \%)$ & $3(37.5 \%)$ & $23(47 \%)$ \\
\hline Unintentional weight loss & $14(34.1 \%)$ & $3(37.5 \%)$ & $17(34.7 \%)$ \\
\hline Excessive sweating & $14(34.1 \%)$ & $3(37.5 \%)$ & $17(34.7 \%)$ \\
\hline Emotional lability & $13(31.7 \%)$ & $4(50 \%)$ & $17(34.7 \%)$ \\
\hline Reduced exercise tolerance & $13(31.7 \%)$ & $3(37.5 \%)$ & $16(32.7 \%)$ \\
\hline Shortness of breath & $11(26.8 \%)$ & $0(0 \%)$ & $11(22.4 \%)$ \\
\hline Chest pain & $10(24.4 \%)$ & $0(0 \%)$ & $10(20.4 \%)$ \\
\hline Insomnia & $9(22 \%)$ & $0(0 \%)$ & $9(18.4 \%)$ \\
\hline Heat intolerance & $7(17.1 \%)$ & $2(25 \%)$ & $9(18.4 \%)$ \\
\hline Difficulty swallowing & $8(19.5 \%)$ & $1(12.5 \%)$ & $9(18.3 \%)$ \\
\hline
\end{tabular}

Table III. Prevalence of coexistent symptoms in one patient

\begin{tabular}{lcc}
\hline Number of symptoms & Number of patients & Percentage (\%) \\
\hline 0 & 8 & $16.3 \%$ \\
\hline 1 & 3 & $6.1 \%$ \\
\hline 2 & 2 & $4.1 \%$ \\
\hline 3 & 8 & $16.3 \%$ \\
\hline 4 & 17 & $34.7 \%$ \\
\hline 5 & 6 & $12.2 \%$ \\
\hline 6 & 3 & $6.1 \%$ \\
\hline 7 & 1 & $2.0 \%$ \\
\hline 8 & 1 & $2.0 \%$ \\
\hline Total & 49 & $100 \%$ \\
\hline
\end{tabular}

The occurrence of coexistent symptoms in one patient was analysed as shown in Table III.

Eight patients $(16.3 \%)$ were completely asymptomatic. Three patients $(6.1 \%)$ suffered from one symptom, and only one patient $(2.0 \%)$ suffered from the maximum number of symptoms - nine. Prevalence of four symptoms in one patient was observed in 17 subjects (34.7\%).

\section{Effects of ${ }^{131}$ I treatment}

One month after ${ }^{131} \mathrm{I}$ therapy 19 patients (38.8\%) reverted to euthyroidism, two patients $(4.1 \%)$ developed hypothyroidism, and 28 patients $(57.1 \%)$ still suffered from SCH (Tab. IV).

After three months 32 patients $(65.3 \%)$ reverted to euthyroidism, seven patients $(14.3 \%)$ developed hypothyroidism, and only 10 patients $(20.4 \%)$ still suffered from SCH.

After six months as many as 33 patients (67.4\%) reverted to euthyroidism, 10 patients $(20.4 \%)$ developed hypothyroidism, and only six patients $(12.2 \%)$ still suffered from $\mathrm{SCH}$.

After 12 months 30 patients $(61.2 \%)$ reverted to euthyroidism, 13 patients (26.5\%) developed hypothyroidism, and six patients (12.2\%) still suffered from $\mathrm{SCH}$.

In majority of patients (87.8\%) RIT was effective.

To sum up, after the complete follow-up, targeted therapeutic results were observed in 43 patients $(87.8 \%)$; 30 patients $(61.2 \%)$ reverted to euthyreosis and 13 patients $(22.5 \%)$ became hypothyroid, as shown in Table V and Figure 2.

\section{Relationship between ${ }^{131}$ I therapy efficacy, gen- der, positive thyroid history, and location of the nodule}

In the analysis of the efficacy of ${ }^{131}$ I therapy after one, three, six, and 12 months with regard to patient's gender, positive thyroid history, and location of the nodule as well as whether the subjects reverted to euthyroidism or developed hypothyroidism with regard to patient's gender, positive thyroid history and location of the nodule, the treatment was found effective only one or three months after the therapy in the patients with focal lesions in the right lobe.

\section{Discussion}

The results of our study point to the symptomatic course of AFTNs in SCH despite persistent normal thyroid hormones. In the study group most patients $(83.7 \%)$ suffered from typical symptoms of hyperthyroidism, and only every sixth patient was asymptomatic. Stott et al. presented similar results for patients aged 61-90 years with $\mathrm{SCH}$ as compared to healthy controls [11]. In the study by Biondi et al. the scores of the Symptoms Rating Scale and the Short Form 36 Health Survey 
Table IV. Effects of ${ }^{131}$ I treatment after 1, 3, 6, and 12 months

\begin{tabular}{|c|c|c|c|c|}
\hline Parameter & Women N (\%) & Men N (\%) & Total N (\%) & $\mathbf{p}$ \\
\hline \multicolumn{5}{|c|}{1 month after treatment } \\
\hline Euthyreosis & $\begin{array}{c}17(41.5 \%) \\
\text { (34.7\% of all patients) }\end{array}$ & $\begin{array}{c}2(25.0 \%) \\
\text { (4.1\% of all patients) }\end{array}$ & $\begin{array}{c}19 \\
\text { (38.8\% of all patients) }\end{array}$ & \multirow{3}{*}{0.34} \\
\hline Hypothyroidism & $\begin{array}{c}1(2.4 \%) \\
\text { (2.0\% of all patients) }\end{array}$ & $\begin{array}{c}1(12.5 \%) \\
\text { (2.0\% of all patients) }\end{array}$ & $\begin{array}{c}2 \\
\text { (4.1\% of all patients) }\end{array}$ & \\
\hline Hyperthyroidism & $\begin{array}{c}23(56.1 \%) \\
\text { (46.9\% of all patients) }\end{array}$ & $\begin{array}{c}5(62.5 \%) \\
\text { (10.2\% of all patients) }\end{array}$ & $\begin{array}{c}28 \\
\text { (57.1\% of all patients) }\end{array}$ & \\
\hline \multicolumn{5}{|c|}{3 months after treatment } \\
\hline Euthyreosis & $\begin{array}{c}26(63.4 \%) \\
\text { (53.1\% of all patients) }\end{array}$ & $\begin{array}{c}6(75.0 \%) \\
(12.2 \% \text { of all patients) }\end{array}$ & $\begin{array}{c}32 \\
\text { (65.3\% of all patients) }\end{array}$ & \multirow{3}{*}{0.80} \\
\hline Hypothyroidism & $\begin{array}{c}6(14.6 \%) \\
\text { (12.2\% of all patients) }\end{array}$ & $\begin{array}{c}1(12.5 \%) \\
\text { (2.0\% of all patients) }\end{array}$ & $\begin{array}{c}7 \\
\text { (14.3\% of all patients) }\end{array}$ & \\
\hline Hyperthyroidism & $\begin{array}{c}9(21.9 \%) \\
\text { (18.4\% of all patients) }\end{array}$ & $\begin{array}{c}1(12.5 \%) \\
\text { (2.0\% of all patients) }\end{array}$ & $\begin{array}{c}10 \\
\text { (20.4\% of all patients) }\end{array}$ & \\
\hline \multicolumn{5}{|c|}{6 months after treatment } \\
\hline Euthyreosis & $\begin{array}{c}27(65.8 \%) \\
\text { (55.1\% of all patients) }\end{array}$ & $\begin{array}{c}6(75.0 \%) \\
(12.2 \% \text { of all patients) }\end{array}$ & $\begin{array}{c}33 \\
\text { (67.4\% of all patients) }\end{array}$ & \multirow{3}{*}{0.83} \\
\hline Hypothyroidism & $\begin{array}{c}9(21.9 \%) \\
\text { (18.4\% of all patients) }\end{array}$ & $\begin{array}{c}1(12.5 \%) \\
\text { (2.0\% of all patients) }\end{array}$ & $\begin{array}{c}10 \\
(20.4 \% \text { of all patients) }\end{array}$ & \\
\hline Hyperthyroidism & $\begin{array}{c}5(12.2 \%) \\
\text { (10.2\% of all patients) }\end{array}$ & $\begin{array}{c}1(12.5 \%) \\
\text { (2.0\% of all patients) }\end{array}$ & $\begin{array}{c}6 \\
\text { (12.2\% of all patients) }\end{array}$ & \\
\hline \multicolumn{5}{|c|}{12 months after treatment } \\
\hline Euthyreosis & $\begin{array}{c}25(61 \%) \\
\text { (51.0\% of all patients) }\end{array}$ & $\begin{array}{c}5(62.5 \%) \\
(10.2 \% \text { of all patients) }\end{array}$ & $\begin{array}{c}30 \\
\text { (61.2\% of all patients) }\end{array}$ & \multirow{3}{*}{0.99} \\
\hline Hypothyroidism & $\begin{array}{c}11(26.8 \%) \\
\text { (22.4\% of all patients) }\end{array}$ & $\begin{array}{c}2(25.0 \%) \\
\text { (4.1\% of all patients) }\end{array}$ & $\begin{array}{c}13 \\
\text { (26.5\% of all patients) }\end{array}$ & \\
\hline Hyperthyroidism & $\begin{array}{c}5(12.2 \%) \\
\text { (10.2\% of all patients) }\end{array}$ & $\begin{array}{c}1(12.5 \%) \\
\text { (2.0\% of all patients) }\end{array}$ & $\begin{array}{c}6 \\
(12.2 \% \text { of all patients) }\end{array}$ & \\
\hline
\end{tabular}

Table V. Effects of ${ }^{131}$ I treatment after 12 months

\begin{tabular}{lcccc}
\hline Parameter & Women N $(\%)$ & Men N $(\%)$ & Total N (\%) & p \\
\hline Effective treatment & $36(87.8 \%)$ & $7(87.5 \%)$ & 43 & 0.57 \\
\hline Hypothyroidism & $(73.5 \%$ of all patients $)$ & $(14.3 \%$ of all patients $)$ & $(87.8 \%$ of all patients $)$ & 13 \\
\hline Euthyreosis & $11(26.8 \%)$ & $2(25.0 \%)$ & $(22.5 \%$ of all patients $)$ & 0.74 \\
\hline
\end{tabular}

questionnaires showed increasing prevalence of typical symptoms of hyperthyroidism that worsened the quality of life of the patients, which correlated with TSH levels [12,13]. Gulseren et al. presented worse results of both mental and physical tests performed by $\mathrm{SCH}$ patients as compared to the control group [14]. In the clinical picture of hyperthyroidism literature stresses greater frequency of symptoms related to the adrenergic overactivity expressed most often by heart palpitation present particularly in young and middle-aged patients. In the study group the feeling of tachycardia was the most frequently reported sign in women (52.2\%) and one of the most common in men (37.5\%). In their study, Sgarbi et al. found a significant increase in atrial and ventricular premature beats in $\mathrm{SCH}$ patients and observed that TSH and $\mathrm{FT}_{4}$ significantly correlated with such premature beats [15]. The meta-analysis conducted by Collet et al. showed higher total and cardiovascular mortality and prevalence of atrial fibrillation in $\mathrm{SCH}$ patients as compared to healthy controls [6]. Such documented effect of SCH on the cardiovascular system suggests considering treatment also in young patients 


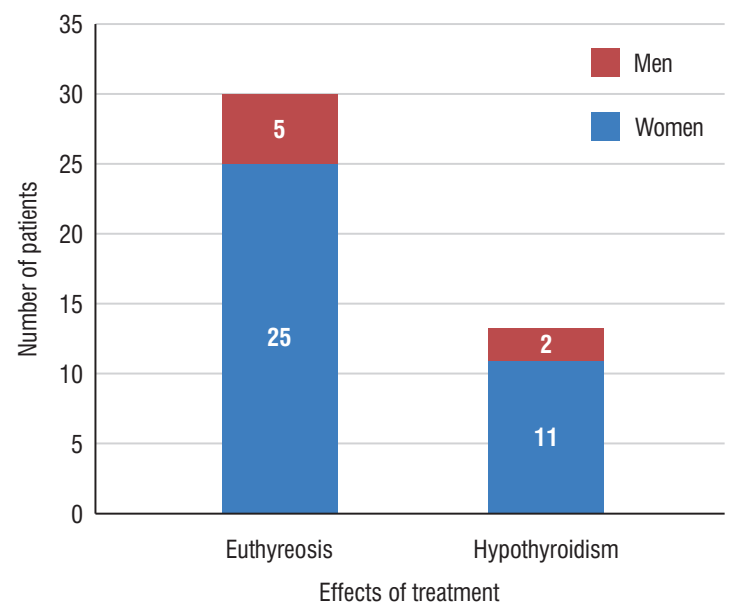

Figure 2. Effects of ${ }^{131}$ I treatment after 12 months

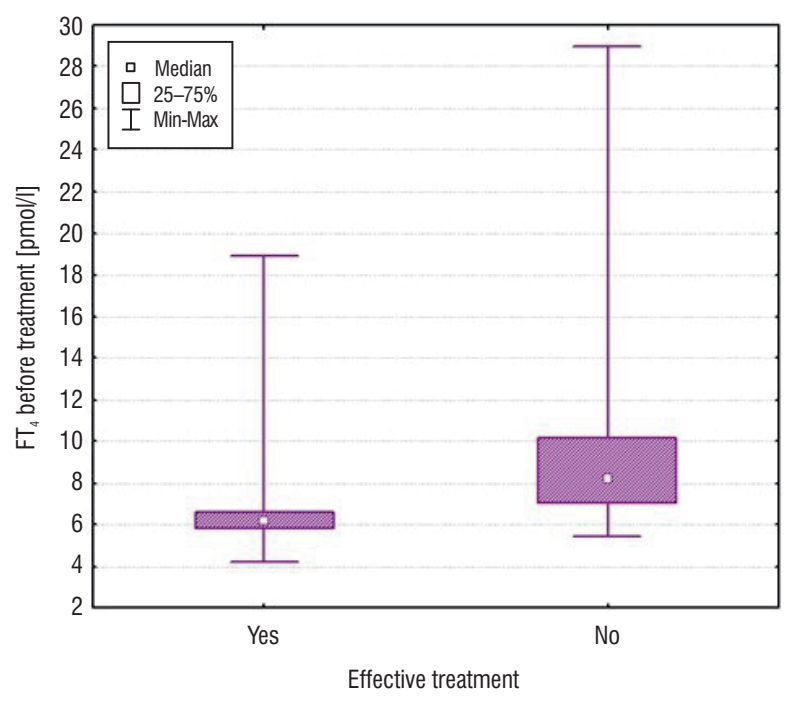

Figure 4. Relationship between initial $\mathrm{FT}_{3}$ level and effects of ${ }^{131}$ I treatment

in order to prevent cardiovascular risk and to improve their quality of life. Our study group showed that the clinical symptoms were not limited to the cardiovascular system. Coexistence of four symptoms in one patient was found in as many as 17 subjects $(34.7 \%)$, which means that every third patient had at least four symptoms typical for overt hyperthyroidism. In the study group $31.7 \%$ of women and $50 \%$ of men complained about emotional lability. The study carried out on the basis of the Beck Anxiety Inventory showed that $\mathrm{SCH}$ patients had significantly higher scores of anxiety than their healthy controls [16].

In Poland ${ }^{131}$ I therapy is the treatment of choice in patients suffering from hyperthyroidism in the course of AFTNs, especially over the age of 60 years, who also suffer from cardiovascular diseases [17]. In our study, in the majority of the patients $(87.7 \%)$, RIT

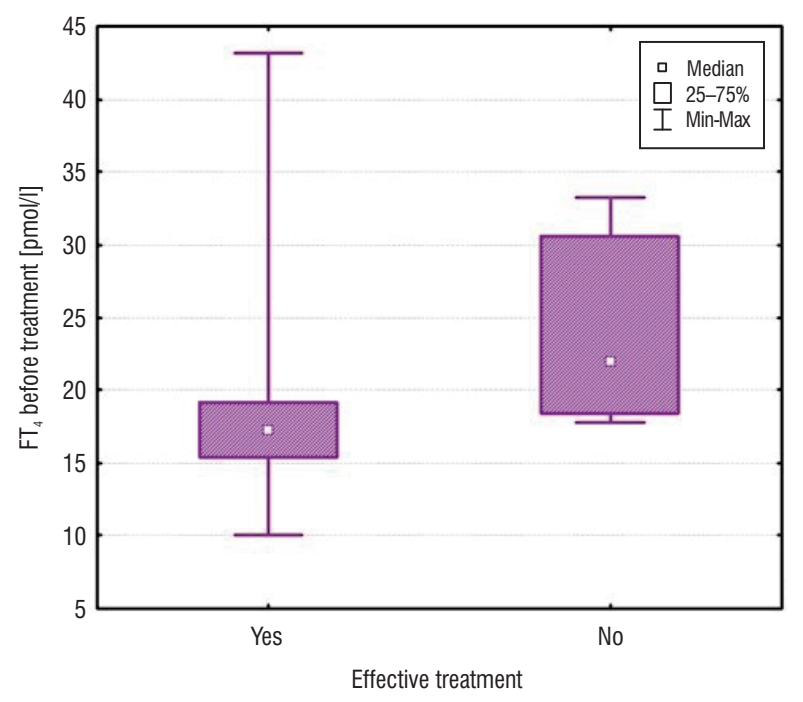

Figure 3. Relationship between initial $\mathrm{FT}_{4}$ level and effects of ${ }^{131}$ I treatment

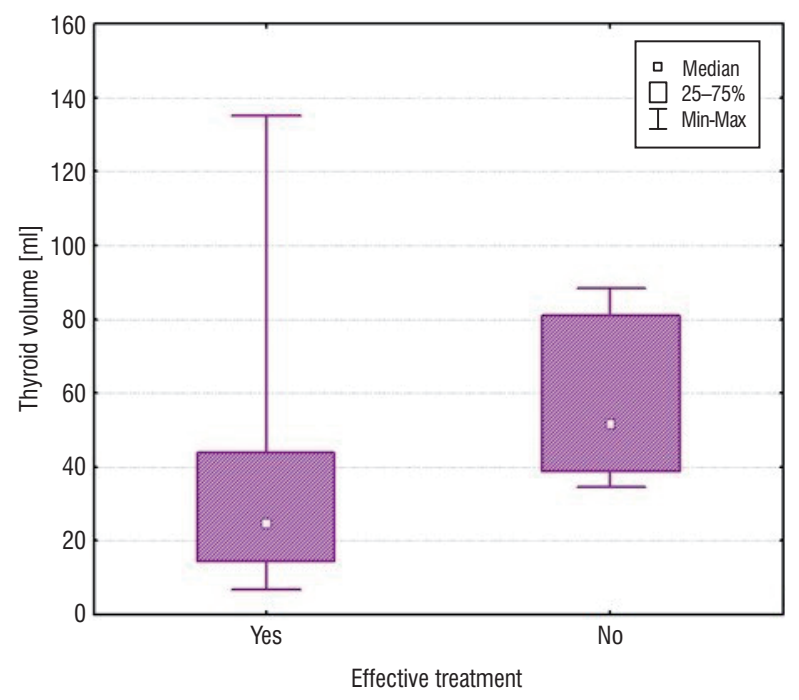

Figure 5. Relationship between the volume of the thyroid gland and effects of ${ }^{131}$ I treatment

treatment was effective. After the complete follow-up of 12 months from ${ }^{131}$ I therapy good therapeutic results were observed in 43 patients (87.8\%); 30 patients $(61.2 \%)$ reverted to euthyroidism and 13 patients $(22.5 \%)$ developed hypothyroidism. Our results were more encouraging than those of the Australian study (79.5\% efficacy) [18]. In the study conducted by Goldstein et al. $35 \%$ of SCH patients treated with ${ }^{131}$ I observed from 4 to 16.5 years developed hypothyroidism, and its prevalence was not dependent on the size of the nodules, thyroid function, or ${ }^{131}$ I dose [19]. However, Mariotti et al. reported hypothyroidism only in $4 \%$ of the patients and found no correlation between the development of hypothyroidism and the size of the nodules or the therapeutic dose of ${ }^{131}$ [ [20]. Bolu- 
sani et al. included 105 patients with AFTNs in their study and observed a rising rate of hypothyroidism over time, i.e. in $11 \%$ after one year, in $33 \%$ after five years, and in $49 \%$ after 10 years following treatment. The development of hypothyroidism did not correlate with age, gender, radioiodine uptake, and activity in therapy [21].

Our study showed correlation between the number of coexistent symptoms before the treatment and the result of SCH therapy in the course of AFTNs. The patients who reported the largest number of symptoms reverted to euthyreosis or still suffered from $\mathrm{SCH}$. However, the patients who reported the smallest number of symptoms developed hypothyroidism. In the analysis of these symptoms and their impact on the effect of treatment significant correlation was found only in terms of emotional lability. We demonstrated that high initial free thyroid hormone levels predisposed patients to poorer therapeutic effects. In most of the patients the nodule was found in the right lobe $(59.2 \%)$, whereas in $20(40.8 \%)$ patients it was found in the left one; in $48.8 \%$ of women the nodule was located in the left lobe. Interestingly, all AFTNs in men were located in the right lobe, for which the literature found no explanation either in terms of anatomy or genetics.

Our results showed no link between the volume of the nodule and treatment efficacy probably due to the small volume of the nodule in our study group.

Although ${ }^{131}$ I therapy was performed when extranodular thyroid tissue was suppressed, the larger thyroid volume translated into poorer treatment effect. This is a surprising observation of the studied population, which requires confirmation in further studies with larger groups of patients. Nonetheless, Rong et al., who examined the above relationship, found no such correlation [22]. Also, Massaroi et al. reported no link between the size of the thyroid and the effect of ${ }^{131}$ I therapy [23].

In our study group the targeted therapeutic effect one and three months after treatment was significantly more frequent in patients with focal lesions located in the right lobe. Such a finding may allow selection of a group of patients who reach therapeutic effects much faster, and at the same time it may serve as a reason to consider various follow-up periods in patients with nodules in the left and right lobe. It seems that such observations should be confirmed in further studies with a larger number of patients because the available literature reports no associations between the quality and quantity of clinical symptoms and the effect of ${ }^{131}$ I therapy.

The coexistence of symptoms typical for overt hyperthyroidism, which was observed in every third patient with $\mathrm{SCH}$, may serve as a basis for modifying the definition of this endocrinopathy and consequently changing the qualifications for treatment. Distinct clinical pictures of SCH point to the necessity for thorough and early diagnostics and treatment, especially in patients with high cardiovascular risk. Because the treatment of this form of disease is currently controversial and the recommendations of international endocrine associations are heterogeneous and often questioned by renowned endocrinologists, our conclusions could serve as valid input in the current debate.

\section{Conclusions}

1. Most patients with $\mathrm{SCH}$ in the course of AFTNs suffer from typical symptoms of overt hyperthyroidism; only every sixth patient was asymptomatic.

2. The volume of autonomous adenomas does not affect the result of ${ }^{131}$ I therapy; however, the impact of the thyroid volume on RIT efficacy requires further investigation.

3. In the vast majority of the patients ${ }^{131} \mathrm{I}$ therapy is an effective method of treatment and an earlier therapeutic effect is observed more often in patients with focal lesions located in the right lobe.

\section{References}

4. Surks MI, Ortiz E, Daniels GH, et al. Subclinical thyroid disease: scientific review and guidelines for diagnosis and management. JAMA. 2004; 291(2): 228-238, doi: 10.1001/jama.291.2.228, indexed in Pubmed: 14722150.

5. Strachan MWJ, Walker BR. Choroby układu wewnątrzwydzielniczego. In: Boon NA, Colledge NR, Walker BR. ed. Choroby wewnętrzne Davidsona. Vol. 2. Elsevier Urban \& Partner, Wrocław 2009: 646.

6. Biondi B, Bartalena L, Cooper DS, et al. The 2015 European Thyroid Association Guidelines on Diagnosis and Treatment of Endogenous Subclinical Hyperthyroidism. Eur Thyroid J. 2015; 4(3): 149-163, doi: 10.1159/000438750, indexed in Pubmed: 26558232.

7. Sowiński J, Lewiński A. Choroby tarczycy. In: Milewicz A. ed. Endokrynologia kliniczna. Vol. II. Polskie Towarzystwo Endokrynologiczne, Wrocław 2012: 266

8. Moreno-Reyes R, Kyrilli A, Lytrivi M, et al. Is there still a role for thyroid scintigraphy in the workup of a thyroid nodule in the era of fine needle aspiration cytology and molecular testing? F1000Res. 2016; 5 , doi: 10.12688/f1000research.7880.1, indexed in Pubmed: 27158470.

9. Collet TH, Gussekloo J, Bauer DC, et al. Thyroid Studies Collaboration. Subclinical hyperthyroidism and the risk of coronary heart disease and mortality. Arch Intern Med. 2012; 172(10): 799-809, doi: 10.1001/archinternmed.2012.402, indexed in Pubmed: 22529182

10. Biondi B, Cooper DS. The clinical significance of subclinical thyroid dysfunction. Endocr Rev. 2008; 29(1): 76-131, doi: 10.1210/er.2006-0043, indexed in Pubmed: 17991805

11. Jarząb B, Lewiński A, Płaczkiewicz-Jankowska E. Choroby tarczycy. In Gajewski P, Szczeklik A. ed. Interna Szczeklika. Medycyna Praktyczna, Kraków 2015: 1275-1277.

12. Cooper DS, Biondi B. Subclinical thyroid disease. Lancet. 2012; 379(9821): 1142-1154, doi: 10.1016/S0140-6736(11)60276-6, indexed in Pubmed: 22273398

13. Jarząb B, Sporny S, Lange D, et al. Diagnostyka i leczenie raka tarczycy — rekomendacje polskie. Endokrynol Pol. 2010; 61(5): 518-568, indexed in Pubmed: 21049469.

14. Stott DJ, McLellan AR, Finlayson J, et al. Elderly patients with suppressed serum TSH but normal free thyroid hormone levels usually have mild thyroid overactivity and are at increased risk of developing overt hyperthyroidism. Q J Med 1991; 78(285): 77-84, indexed in Pubmed: 1670067.

15. Biondi B, Palmieri EA, Fazio S, et al. Endogenous subclinical hyperthyroidism affects quality of life and cardiac morphology and function in young and middle-aged patients. J Clin Endocrinol Metab. 2000; 85(12): 4701-4705, doi: 10.1210/jcem.85.12.7085, indexed in Pubmed: 11134131. 
16. Tylka J, Piotrowicz R. Kwestionariusz oceny jakości życia SF-36 — wersja polska. Kardiol Pol. 2009; 67: 1166-1169.

17. Gulseren S, Gulseren L, Hekimsoy Z, et al. Depression, anxiety, health-related quality of life, and disability in patients with overt and subclinical thyroid dysfunction. Arch Med Res. 2006; 37(1): 133-139, doi: 10.1016/j. arcmed.2005.05.008, indexed in Pubmed: 16314199.

18. Sgarbi JA, Villaça FG, Garbeline B, et al. The effects of early antithyroid therapy for endogenous subclinical hyperthyroidism in clinical and heart abnormalities. J Clin Endocrinol Metab. 2003; 88(4): 1672-1677, doi: 10.1210/jc.2002-021046, indexed in Pubmed: 12679455.

19. Grabe HJ, Völzke H, Lüdemann J, et al. Mental and physical complaints in thyroid disorders in the general population. Acta Psychiatr Scand. 2005; 112(4): 286-293, doi: 10.1111/j.1600-0447.2005.00586.x, indexed in Pubmed: 16156836.

20. Brown RS. Autoimmune thyroid disease: unlocking a complex puzzle. Curr Opin Pediatr. 2009; 21(4): 523-528, doi: 10.1097/MOP.0b013e32832cf824, indexed in Pubmed: 19474733.

21. Bahn Chair RS, Burch HB, Cooper DS, et al. American Thyroid Association, American Association of Clinical Endocrinologists. Hyperthyroidism and other causes of thyrotoxicosis: management guidelines of the American Thyroid Association and American Association of Clinical En- docrinologists. Thyroid. 2011; 21(6): 593-646, doi: 10.1089/thy.2010.0417, indexed in Pubmed: 21510801.

22. Goldstein R, Hart IR. Follow-up of solitary autonomous thyroid nodules treated with 131I. N Engl J Med. 1983; 309(24): 1473-1476, doi: 10.1056/NEJM198312153092401, indexed in Pubmed: 6646172.

23. Mariotti S, Caturegli P, Barbesino G, et al. [Radiometabolic therapy of the autonomous thyroid nodule]. Minerva Endocrinol. 1993; 18(4): 155-163, indexed in Pubmed: 8190055.

24. Bolusani H, Okosieme OE, Velagapudi M, et al. Determinants of long-term outcome after radioiodine therapy for solitary autonomous thyroid nodules. Endocr Pract. 2008; 14(5): 543-549, doi: 10.4158/EP.14.5.543, indexed in Pubmed: 18753095.

25. Ronga G, Filesi M, D'Apollo R, et al. Autonomous functioning thyroid nodules and 131I in diagnosis and therapy after 50 years of experience: what is still open to debate? Clin Nucl Med. 2013; 38(5): 349-353, doi: 10.1097/RLU.0b013e318286bbda, indexed in Pubmed: 23531770.

26. Massaro F, Vera L, Schiavo M, et al. Ultrasonography thyroid volume estimation in hyperthyroid patients treated with individual radioiodine dose. J Endocrinol Invest. 2007; 30(4): 318-322, doi: 10.1007/BF03346299, indexed in Pubmed: 17556869. 